\title{
Fire-safe bamboo structures - a methodology to facilitate performance-based design
}

\author{
M. Gutierrez, A. Solarte, I. Pope, C. Maluk \& J. Hidalgo \\ The University of Queensland, School of Civil Engineering, St Lucia, Queensland, Australia \\ J.L. Torero \\ The University of Maryland, A. James Clark School of Engineering, College Park, Maryland, USA
}

\begin{abstract}
Traditionally, bamboo has only been used for structural purposes in lowrise buildings, and one of the main reasons is that the fire performance of load-bearing bamboo structures is not well understood. Before this material can be used in applications where fire safety considerations are critical, for instance in mid-rise buildings or other complex structures, its fire performance must be characterised comprehensively. This requires an understanding of the fire-induced failure mechanisms and mechanical performance at elevated temperatures of bamboo structural elements, as well as their thermal performance and burning behaviour. The work described herein summarises the knowledge gaps and engineering challenges that must be overcome to facilitate the performance-based design of bamboo structures. A continuing holistic study aimed at addressing these issues is introduced. Key thermal and mechanical properties and burning behaviours of both laminated and round bamboo are summarised.
\end{abstract}

\section{INTRODUCTION}

While round bamboo has been widely used in traditional low-rise construction for millennia, engineered bamboo products are novel construction materials that share many of the attractive qualities of engineered timber products, which are becoming increasingly popular for use as a primary structural material in mid- and high-rise buildings. Engineered bamboo structural elements possess a high strength-to-weight ratio and aesthetic value, while reducing the variabil-ity and difficulties of connections associated with the natural material (Sharma et al. 2014). Fur-thermore, bamboo has significant potential for sequestering carbon, and may often be more readily available than timber in regions with large populations and developing economies, including Latin America, Africa, and East Asia (Yiping et al. 2010). As a combustible material, the use of bamboo in construction has thus far been constrained to secondary applications or low-rise buildings, due to a lack of research and understanding of its fire performance.

To ensure life safety in building fires, tenable conditions must be maintained along egress routes until all occupants have reached a safe space. Additionally, the structure must be resilient to the effects of the fire throughout egress and firefighter intervention, and as appropriate to prevent damage to neighbouring property. For tall buildings with very long egress times, this second requirement effectively means that the structure must survive the whole duration of the fire until burnout and through the cooling period. However, occupants of low-rise buildings may typically exit the building before the fire has grown sufficiently to begin compromising the structure, and firefighters can often intervene externally when necessary.

For a lignocellulosic material such as bamboo, the question of fire safety is therefore dependent on a series of interrelated factors, whose relative significance is influenced by the context and scale at which the material is used in a building (Reszka \& Torero 2016). The chemical and thermal properties of the material - as well as its use and configuration in the building - govern the parameters of flammability, flame spread, and heat release rate, which 
determine its contribution to the growth of the fire. These affect the development of untenable conditions within the building, and therefore the available time for occupants to egress safely, but potentially also the thermal loading on the structure. Thermal properties and burning behaviour, such as charring, also dictate the heat-transfer and development of temperature profiles through structural elements. This feeds back into the dynamics of the fire, but also the performance of the structure, since the mechanical properties of bamboo have been shown to be greatly affected by elevated temperature (Gutierrez Gonzalez et al. 2018, Xu et al. 2017, Mena et al. 2012). Therefore, in order to ensure the fire-safe design of bamboo structures it is essential to analyse all of these factors holistically, and with due consideration of the context of the building and its occupants. This document will outline the research methodology required to address most of these factors, and to provide tools for engineers and practitioners to understand how to design fire-safe bamboo structures.

\section{MATERIAL PROPERTIES AND FLAMMABILITY}

The characterisation of bamboo's performance under fire conditions requires fundamental knowledge of the thermal degradation and flammability properties of its components, because these will determine the onset of hazard. With this understanding, a methodology could be established to determine how the material affects the development of the fire and the safety of occupants within a building. The comprehension of bamboo's physical, thermal, and flammability behaviour properties is of key importance, and serves as a starting point for analysis.

\subsection{Thermal characterisation}

Woody bamboos are mainly composed of polymers that undergo different transformations when exposed to heat. The anatomical structure of bamboo can be described as a two-phase composite of vascular bundles and parenchyma tissue (Amada et al. 1997). The vascular bundles are mainly made of fibre bundles and vessels, and the parenchyma tissue is a porous media in which the fibre bundles are embedded (Liese 1998). The bamboo fibres are made of approximately $73.8 \%$ cellulose, $10.1 \%$ lignin and $12.5 \%$ hemicellulose (Wang et al. 2009). The parenchyma cells have a relatively similar content of cellulose $(68.8 \%)$, but it is much less lignified than the fibre bundles and it is characterised by having thinner cell walls, large cell cavities, and larger and more pits compared to bamboo fibre bundles (Wang et al. 2015). When subjected to heating, these polymers can experience a chemical decomposition, also known as pyrolysis. During pyrolysis the bamboo will yield products resulting in a mixture of volatile gases, called pyrolysates, and in reaction with oxygen can sustain flaming combustion (Drysdale 2011). Therefore, it can be said that the onset of hazard for flame spread and fire growth is when the material reaches a pyrolysis temperature that will enable ignition.

Thermogravimetric analysis of bamboo conducted in oxygen shows three distinct phases. For temperatures between ambient and $150^{\circ} \mathrm{C}$, the material suffers some mass loss due to the evaporation of water within the cellular walls and cavities (free and hygroscopic water). At temperatures above $150^{\circ} \mathrm{C}$ and below $400^{\circ} \mathrm{C}$, the material experiences the highest loss of mass. Around $165^{\circ} \mathrm{C}$, the derivative of mass loss from thermogravimetric data (DTG) shows that the mass loss rate of bamboo starts to increase significantly. This can be identified as the point of the initiation of pyrolysis until the hemicellulose and cellulose reach the peak of volatilisation at $287^{\circ} \mathrm{C}$ and $333^{\circ} \mathrm{C}$ respectively, where the maximum thermal degradation is observed (Chen et al. 2015, Jiang et al. 2012, Wang et al. 2008). The DTG starts to decrease after this, and at $400^{\circ} \mathrm{C}$ it can be observed that bamboo has already lost about $70 \%$ of its mass. At temperatures above $400^{\circ} \mathrm{C}$, the material continues losing mass at a lower rate thanks to the oxidation of the char, until only the inorganic material remains, and the TGA shows approximately $20-25 \%$ of residual mass at $900^{\circ} \mathrm{C}$ (Mi et al. 2016, Jiang et al. 2012).

Another key parameter to understand the fire performance of bamboo structures is to characterise the heat transfer mechanisms of this material. To do this, the thermal physical properties - 
density $(\rho)$, thermal conductivity $(k)$ and specific heat capacity $\left(C_{p}\right)$ - and thermodynamic properties of bamboo - thermal inertia $\left(k \rho C_{p}\right)$ and thermal diffusivity $(\alpha)$ - need to be identified.

Compared to engineered timber products such as Glulam, engineered bamboo products have a higher density (Sharma et al. 2015), and a higher thermal conductivity (Solarte et al. 2018). The thermal conductivity is a property that drives a material's ability to conduct heat, and it determines the rate at which energy is transported by the diffusion process. A material with a high thermal conductivity and density will result in a material with high thermal inertia. The thermal inertia is the product of the thermal conductivity, the density and the specific heat capacity $\left(k \rho C_{p}\right)$, and is the resistance of a material to change its surface temperature. In other words, it measures how quickly the surface temperature of a material increases when exposed to heat. Materials with high values of thermal inertia require higher energy or heat flux to increase their surface temperature, so in comparison with timber, laminated bamboo products will require more energy to ignite. Thermal diffusivity $(\alpha)$ is another important property to identify, and it is calculated from the ratio between the thermal conductivity and the product of density and specific heat. This measures the ability of a material to conduct thermal energy relative to its ability to store it. The larger the thermal diffusivity, the faster the temperature will increase at a certain depth in a material (Drysdale 2011). In comparison with engineered timber products, the heat wave may penetrate in a faster manner through bamboo structures. Hence elevated temperatures inside a structural element could reach farther than in timber.

The characterisation of the thermal degradation of bamboo structures is important for design, because even if at this stage the material has not ignited, it does not necessarily mean that the building is fire safe. Even when there is no flaming combustion, pyrolysis can produce toxic gases that can affect people before evacuation. Before the onset of ignition, the structure may also lose integrity due to phase changes (e.g. glass transition) enabled by the transfer of heat through the cross-section.

\subsection{Flammability}

Once the thermal properties have been characterised, and pyrolysis temperatures have been identified, the next step to design fire safe bamboo buildings is to identify the conditions in which ignition takes place. The quantification of flammability in materials is fundamental because it determines the general fire behaviour, size and fire spread, which all control the development of untenable conditions within a building, i.e. conditions that are hazardous to the health and safety of occupants.

To determine the ignition conditions of bamboo, two main steps determine the characterisation of flammability for this methodology. First, obtaining parameters such as the critical heat flux for piloted ignition $\left(q_{c r}\right.$ "), and time and temperature for ignition $\left(t_{i g}, T_{i g}\right)$ as stated by Torero (Torero 2013). The critical heat flux for ignition is the highest heat flux at which ignition does not take place, i.e. the material will ignite at any higher heat flux than this. This is obtained experimentally by testing samples and obtaining the time it takes to ignite at various heat fluxes. (Torero 2013). Secondly, analysing the burning process of the material by determining the critical mass loss rate at the initiation of sustained flaming combustion (Solarte et al. 2018, Rasbash et al. 1986).

Another flammability aspect to consider for design is how the flame will spread and contribute to fire growth inside a compartment or façade made of bamboo. This is a mechanism in which a flame moves forward in the vicinity of a pyrolysing region of the surface fuel (Fernadez-Pello et al. 1983). There are two major phenomena that need to be characterised in the understanding of flame spread: (1) opposed flow flame spread, and (2) concurrent flow flame spread (Fernadez-Pello et al. 1983). Opposed flow flame spread addresses the scenario in which the flame front is moving forward against the flow of air, only preheating the unburned fuel immediately ahead of the flame front. Upward vertical flame spread is an example of concurrent flow flaming, and in this case the flow is pushing in the same direction as the flame, effectively "driving" it forward and enabling faster propagation by preheating the material further ahead of the flame. 
In the event of a fire, a safe evacuation needs to be guaranteed. This means that every person should have enough time to egress before untenable conditions are reached. Untenable conditions may be caused by reduced visibility and elevated toxicity due to smoke, or high temperatures and heat fluxes within the building, all of which are intrinsically linked to the growth and spread of the fire. Once the flame spread parameters of the material are established, the rate at which the fire will grow and contribute to the production of heat and smoke may be estimated. By understanding this behaviour, it is possible to design a bamboo building in which the development of untenable conditions will not occur until after the safe evacuation of the building.

\section{THERMAL BEHAVIOUR}

The burning behaviour of bamboo, like timber, is characterised by a series of chemical and physical changes occurring over a wide range of temperatures. As detailed in Section 2.1, these changes are related to the different components of the material, which are predominantly lignin, cellulose, hemicellulose, and water. As the temperature increases, the first effect is the evaporation and migration of moisture, which occurs rapidly around the boiling temperature of $100^{\circ} \mathrm{C}$. This is effectively an endothermic process, due to the extra energy required to evaporate water, but the migrating moisture may also transfer heat through the material. Above $100^{\circ} \mathrm{C}$, all of the free water has been driven out, and the remaining components begin to chemically decompose through the process of pyrolysis (Bartlett et al. 2018b). This peaks in a temperature range of around $200-400^{\circ} \mathrm{C}$ (Chen et al. 2015, Jiang et al. 2012), as the cellulose, hemicellulose and lignin volatilise and are converted into char, which is primarily composed of carbon. As temperatures rise further, exothermic oxidation reactions take place within the char, providing an additional heat source and resulting in gradual regression of the char layer (Bartlett et al. 2018b).

In a structural member under transient heating, these processes occur over different temperature zones that move through the section as the heat wave travels from the exposed surface. As a simplification, these regions are often delineated by isotherms that correspond to the critical temperatures for each process. Typically, the region below $100^{\circ} \mathrm{C}$ is assumed to possess the thermal properties - density, conductivity and heat capacity - of the virgin material. Between this 'normal zone' and the $300^{\circ} \mathrm{C}$ isotherm is the 'dry zone', from which all of the moisture has been removed and the thermal properties are altered accordingly. Above $300^{\circ} \mathrm{C}$, the material is commonly assumed to have the thermal properties of char, which typically has much lower density and conductivity, so acts as an insulating barrier protecting the material beneath. However, charring is associated with shrinkage and thermal stresses that induce cracking of the charred material, locally compromising this insulation (Reszka \& Torero 2016). It should be noted that these critical temperatures are approximations, and in reality the various processes will occur over temperature ranges that are dependent upon the heating rate and the exact chemistry of the material. Therefore, the boundaries of these temperature zones should be experimentally validated before they can be used for design purposes. Similarly, the density, conductivity and heat capacity are key determinants of heat transfer through solids, so it is essential to characterise these values over the different regions in order to predict how temperature profiles will develop in-depth during a fire.

\subsection{Implications for structural fire performance models}

For round bamboo culms, with wall thicknesses of typically only 10-20 mm, structural members exposed to fire conditions are likely to reach critical failure temperatures rapidly, particularly since the fibres that contribute most to loadbearing capacity are concentrated near the surface. In this scenario, coupled thermal and structural models are likely to be redundant, since the exposed structural elements might conservatively be expected to fail shortly after the fire has developed. However, where round bamboo elements are protected by other insulating components - as may be the case in stud wall systems such as 'bahareque' structures - the heating rate will be lower, and transient thermal models may provide a useful input for 
predictions of structural degradation. This would also require modelling heat flow through the insulating elements, and analysis of the whole system.

For 'engineered' bamboo products, such as laminated bamboo or bamboo scrimber, the cross-sections of structural elements can be made much thicker, allowing for an insulating char layer to form while some structural capacity is maintained by the inner material. In this case, the development of elevated temperatures ahead of the charring front may become significant in determining the residual structural capacity. Another characteristic of engineered bamboo products is the role of adhesives in binding together the bamboo components into a composite material. Whether in the form of discrete adhesive layers between bamboo strips, or an amorphous resin matrix binding bamboo fibre bundles, as is the case for products like bamboo scrimber, the performance of the glue is critical to the overall behaviour of the structure. Many common structural adhesives begin to degrade at temperatures as low as $100-300^{\circ} \mathrm{C}$ (Clauß et al. 2011), potentially resulting in delamination of the outer lamellae or a premature loss of strength under fire conditions. Delamination of the outer bamboo layers can totally compromise the insulating effect of the char layer, allowing additional heat to reach the virgin material. A necessary condition for a bamboo structure to survive a fully developed fire is that it will eventually stop burning of its own accord, once the other combustible contents have been consumed by the fire. This process, called 'self-extinction', is a result of the increasing char layer limiting the amount of energy that can pyrolyse the unburnt material, until it is below the minimum required to sustain burning. Progressive delamination can critically undermine the self-extinction process, so it is vital to be able to predict if or when each glue layer might reach its failure temperature in order to assess this potential.

A standard approach for timber structures in fire is to assume a nominal charring rate of around $0.6-0.7 \mathrm{~mm} / \mathrm{min}$ to approximate the movement of the charring front, ahead of which is an assumed 'heated depth' of $7 \mathrm{~mm}$ (CEN 2004). This depth is assumed to account for the reduced strength of the material heated above ambient but below the charring temperature, and the material in this region is assumed to have no structural capacity. By subtracting the assumed zero-strength char layer and heated depth, the residual capacity of the structural member is calculated for a particular fire exposure time. While it may seem reasonable to apply this approach to engineered bamboo structures, due to the chemical similarities of timber and bamboo, it has been found that this method cannot predict structural performance at certain fire exposures (Bartlett et al. 2018a). This has been attributed to a much larger heated depth observed in laminated bamboo fire experiments, which is likely due to the fact that bamboo has substantially different thermal properties than the timbers for which this method has been developed. In particular, the thermal conductivity of laminated bamboo has been found to be approximately double that of timber (Solarte et al. 2018, Bartlett et al. 2018a), which results in faster in-depth heating.

Therefore, the performance-based design of bamboo structures requires a specific understanding of how the materials behave under fire conditions, and experimentally validated thermal models to predict the in-depth temperature rise under a range of heating conditions. These predictions can then inform tailored structural models that account for the unique material behaviour at elevated temperatures.

\section{STRUCTURAL FIRE PERFORMANCE}

\subsection{Thermal degradation of bamboo}

Normally, the rise of temperatures can lead to several chemical and physical transformations in a material, and in most of those cases, these changes immediately compromise the strength and load-bearing capacity. As it was already mentioned, bamboo compounds experience thermal degradation at different temperatures affecting their strength, and stiffness. Before the mass loss due to evaporation of water, several authors have reported that lignin suffers a significant loss of stiffness at around $60-70^{\circ} \mathrm{C}$, based on previous studies of the dynamic mechanical analysis (DMA) of bamboo (Reszka and Torero 2016, Liu et al. 
2012, Ramage et al. 2017). It is well known that one of the methods used to bend bamboo poles utilises localised high-temperature to soften the bamboo cross-section, allowing to bend the pole into different shapes through the use of jigs (Hidalgo López 2003). Additionally, it has been reported that when thermal modification is applied to engineered bamboo products, a softening of the bamboo cross-section is achieved. When bamboo is treated with temperatures of around $150^{\circ} \mathrm{C}$, and then is pressed in the radial direction, it is possible to increase its density due to a reduction of voids and a redistribution of fibres. This will also increase the mechanical properties up to 30\% (Archila Santos et al. 2014, Yang et al. 2016), however, if the temperature applied is above $150^{\circ} \mathrm{C}$, cellulose and hemicellulose will decompose, and the modulus of rupture and the modulus of elasticity will drop compared to the values at ambient temperature (Zhang et al. 2013, Trujillo and López 2016).

A comprehensive thermo-chemical characterisation should be conducted to understand the degradation of the different compounds of bamboo, since the fibre bundles and the parenchyma tissue have different effects on the load-bearing capacity of bamboo. Whereas the fibres are mainly responsible for the tensile strength, the parenchyma plays a fundamental role in supporting the fibre bundles under compression, besides giving the strength of bamboo under shear stress parallel to the fibres (Rizal et al. 2018).

TGA results of the bamboo fibres and matrix can explain the thermal degradation and the temperature range at which pyrolysis occurs, identifying mass loss and other phenomena affecting bamboo strength, like the progression of the char front and the reduction of the cross-section. DMA analysis of the bamboo fibres and matrix will help to explain the degradation in the stiffness at different temperatures, and how the material may undergo processes that, even without producing mass loss or pyrolysis reactions, are able to modify the mechanical behaviour, resulting in significant strength losses under different load scenarios. Results from this characterisation will help to understand the reduction of the mechanical properties of the whole bamboo cross section.

\subsection{Mechanical properties of bamboo at elevated temperature}

Several authors have suggested methods to measure the reduction of the mechanical properties of structural materials at elevated temperatures, however Pettersson (1986) suggested that the mechanical behaviour at elevated temperatures can be assessed through either steady state or transient-state tests. Under steady state tests, the cross-section of the loadbearing element is at a constant temperature during testing, and therefore, the test is not dependent on time once the steady state has been reached (Pettersson 1986). At this temperature, tests to measure stress-strain relationships can be conducted under loadcontrolled or strain-controlled rate, as well as other tests at constant stress or constant strain where creep or relaxation can be obtained (Pettersson 1986, Purkiss and Li 2014, Buchanan and Abu 2017).

As with other lignocellulosic materials, bamboo suffers a significant reduction of the mechanical properties at elevated temperatures. Under compression, bamboo's strength is provided by the composite action of fibre and parenchyma (Sharma et al. 2015). The parenchyma tissue gives the fibres lateral support, avoiding the buckling failure of individual fibres. On the other hand, fibres are the primary source of tensile strength in bamboo (Gutierrez Gonzalez et al. 2012). Results from Xu et al. (2017) showed that bamboo scrimber suffers a significant reduction in the mechanical properties at temperatures below $200^{\circ} \mathrm{C}$. $\mathrm{Xu}$ reported that bamboo scrimber samples under compression showed a strength reduction of $55 \%$ at $100^{\circ} \mathrm{C}$, whereas the tensile strength reduction at $100^{\circ} \mathrm{C}$ is around $38 \%$ (Xu et al. 2017). Mena et al. (2012) showed that round and laminated bamboo suffer a reduction in bending strength of approximately $8 \%$ and $18 \%$ respectively at $100^{\circ} \mathrm{C}$ (Mena et al. 2012).

Similar to timber, bamboo scrimber experiences a lower reduction of the modulus of elasticity (MOE) at elevated temperatures compared to the reduction in the compressive and tensile strength. At $100^{\circ} \mathrm{C}$, the $\mathrm{MOE}$ of bamboo scrimber measured in compression presented a reduction of $20 \%$, whereas in tension the reduction is about $12 \%$. 
Despite the indications of these studies regarding the reduction in the mechanical properties of bamboo, there have as yet been no studies reporting the reduction in the compressive, tensile, and shear strength of round and laminated bamboo at elevated temperatures. Thanks to the use of novel set-ups, the reduction of the mechanical properties of round and laminated bamboo is being investigated at The University of Queensland using an environmental chamber, and a heating blanket set-up. The studies will be conducted with samples prepared following the recommendations of ISO 22157 for round bamboo (ISO 2004a, ISO 2004b), and EN 408 for laminated bamboo (European Committee for Standardization 2012), refer to Figure 1. However, some parameters had to be changed due to the conditions for testing at elevated temperatures, or due to the unique conditions of bamboo, which are not addressed in the timber standard. Results from these tests will provide the required information to create constitutive models of bamboo at elevated temperature, and will enable the prediction of the mechanical behaviour of load-bearing elements under transient heating.

\subsection{Load-bearing capacity of bamboo elements under fire}

The understanding of the reduction in the mechanical properties of bamboo at elevated temperature will enable the prediction of the mechanical response of load-bearing elements under different load conditions. For instance, when heat is applied on one side of the element, the combustion of bamboo can lead to charring of the exposed surface. The reduction in the mechanical properties indicates that above a certain temperature, the material cannot withstand load anymore, and it will lose its mechanical resistance (Buchanan and Abu 2017, Buchanan et al. 2014). For temperatures above that value, it can be assumed that the material strength and stiffness is zero, and therefore further analysis should be conducted to understand the correlation between mechanical properties and the temperature gradient over the cross-sectional area, especially where temperatures are between ambient and the temperature at which the strength is assumed to be zero. This analysis can lead to different mechanical behaviours, such as the loss of some parts of the cross-section in certain areas exposed to heat, or to a shift in the neutral axis of the cross-section due to the variation of mechanical properties along the depth.

The capacity to predict the temperature profiles/gradients and the constitutive models of bamboo at elevated temperature is a fundamental input to predict the load-bearing response,
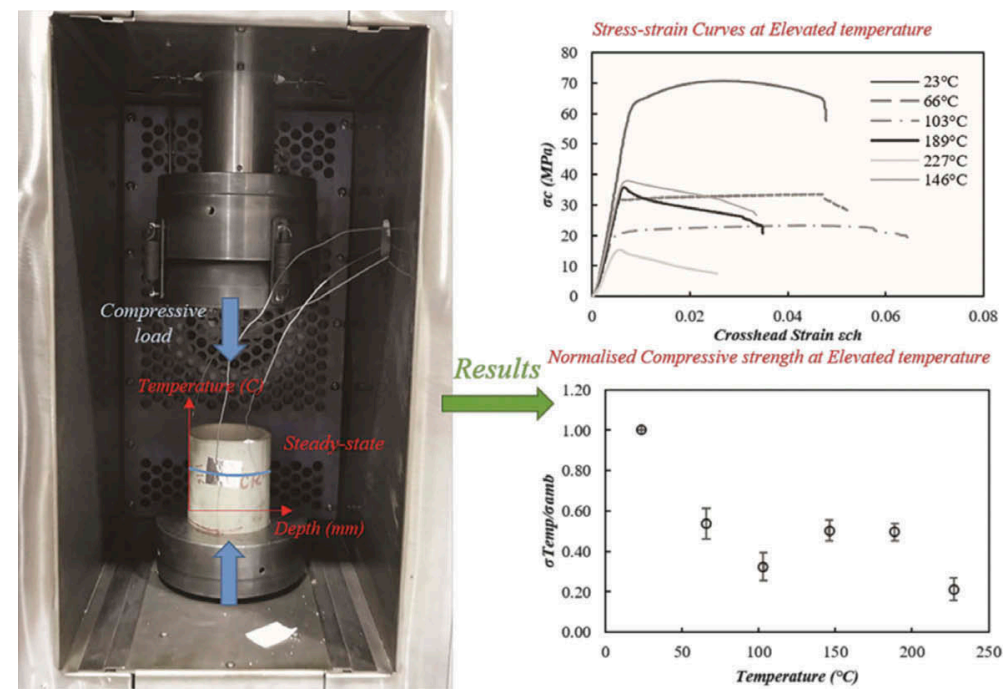

Figure 1. Experimental set-up to measure the reduction in the mechanical properties at elevated temperatures at steady state. 
as is explained in Figure 2. The analysis of deformations, strains, and stress-states during a fire will allow predicting failure loads, displacements and times to failure of single elements, or even structural systems. These design outputs are required for compatibility with other outputs from the fire safety strategy developed to guarantee the safety of occupants, particularly when structural integrity must be provided for the safe evacuation of the building, or for the safety of the fire brigades controlling the fire in a bamboo structure (Östman et al. 2017).

Bearing this in mind, laminated bamboo has shown the capacity to withstand loads under fire for longer periods than round bamboo. Due to the geometry of round bamboo, which normally possesses a small wall thickness, combined with its already reported thermal properties, round bamboo load-bearing elements lose cross-section rapidly, reaching failure loads in short time-periods (Kaminski et al. 2016). Tests on round bamboo have shown that thermal gradients are hard to achieve, therefore it is not practical to measure the reduction in the mechanical properties along the cross-section (Gutierrez Gonzalez et al. 2018). The progression of the char front is observed, and the load-bearing capacity of round bamboo elements can be lost rapidly during a typical compartment fire. Understanding the burning behaviour and the structural performance of round bamboo structures during a fire will define the limits of applicability of this material in the urban environment. However, due to the geometry of laminated bamboo, this material is able to create char layers that may provide enough insulation to the inner parts of the cross-section, having residual cross-sections with intact mechanical properties that could help to withstand design loads through the duration of a fire. After understanding the behaviour of laminated bamboo under a fire, this material could have the potential to be used in applications where structural fire safety considerations must be addressed, as has been already seen in high-rise timber buildings made of engineered wood products. Mechanical tests during fire should be conducted to guarantee that loads, deformations, and time to failure could be accurately predicted when designing load-bearing laminated bamboo elements. This will be the basis for understanding the behaviour of bamboo structural systems under fire.

Thermal gradients within the cross-section are also key to predicting other phenomena, like delamination. The reduction in the mechanical properties of the glue at elevated temperatures, as well as the shear stress in the element at the glue line location, will determine whether or not delamination can occur at any point. Delamination is not only important to maintain a certain level of strength in the load-bearing element, but it is also an important parameter to guarantee the conditions of self-extinguishment.
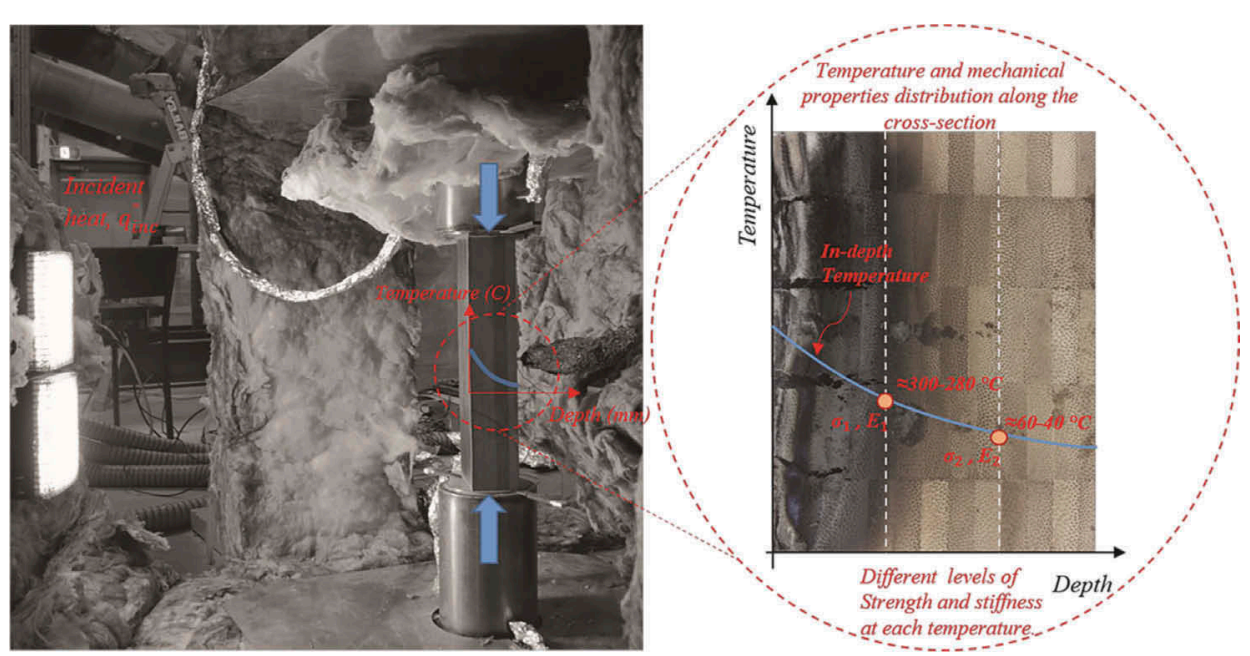

Figure 2. Diagram of the correlation between the thermal behaviour and the mechanical properties of bamboo at elevated temperatures. 


\subsection{Implications of the thermo-mechanical degradation of bamboo in the built environment}

The reduction of the mechanical properties at different temperatures could be included in building codes that require the prediction of the load-bearing capacity of bamboo under fire. Current bamboo codes do not allow building with exposed bamboo elements due to lack of understanding of how load-bearing capacity of bamboo elements can be predicted under exposure to different fire scenarios (ISO 2004c). If designers had the information required to calculate the temperature profile and the reduction in mechanical properties within the bamboo cross-section under any fire scenario, fire and structural engineers would be able to predict the failure of load-bearing elements during a fire. Current prescriptive design frameworks have established different fire resistance levels to prescribe a minimum structural performance within the scope of the whole fire safety strategy. However, these frameworks were created for other conventional materials like concrete and steel. Since these are noncombustible in nature, the current design guidelines will not describe the structural performance of bamboo in an appropriate manner. New design guidelines should be proposed to analyse the structural performance of combustible materials like bamboo, where real fires should be used as the imposed thermal boundary conditions, and where the analysis of their constitutive models at elevated temperatures will be the basis to predict their mechanical response under a fire.

\section{CONCLUSIONS}

To achieve fire safe bamboo structures, it is important to develop new tools that enable a performance-based methodology and take into consideration the complete characterisation of the material, such as the thermal degradation, flammability conditions, heat transfer, and understanding how all of this can affect the structural behaviour of the material and the development of the fire.

The understanding of the intrinsic characteristics of bamboo will determine the different failure modes associated with the structural failure for each specific scenario. This full characterisation will also enable professionals to design with the knowledge required to define realistic fire scenarios, which is fundamental to guarantee that tenable conditions are maintained in the building until occupant egress is complete.

While it is tempting to assume that standard design methodologies used for timber can be applied equally to bamboo products, recent studies have shown that this may not be the case, and that new approaches are required, tailored to the specific materials. This will involve a detailed characterisation of the thermal response of bamboo structural elements under realistic fire conditions so that temperature profiles through the depth of the cross-section can be predicted and used as an input in structural models.

Correct and appropriate testing methodologies and very well-defined thermal boundary conditions are key aspects to assess the reduction in the mechanical properties at elevated temperatures.

The understanding of the reduction of the mechanical properties at elevated temperatures will enable the prediction of the cross-section reduction due to the fire, and it will allow predicting the loss of load-bearing capacity, as well as different failure mechanisms caused by thermal loading.

The understanding of the structural performance of bamboo structures during a fire will allow the bamboo industry to build structures where the fire safety strategy requires guaranteeing structural integrity before and after fire service intervention. A good understanding of the behaviour of bamboo at elevated temperatures, will unlock the capacity of bamboo to be used as a mainstream construction material in urban environments.

\section{REFERENCES}

Amada, S., Ichikawa, Y., Munekata, T., Nagase, Y. \& Shimizu, H. 1997. Fiber texture and mechanical graded structure of bamboo. Composites Part B: Engineering, 28, 13-20. 
Archila Santos, H.F., Ansell, M.P. \& Walker, P. 2014. Elastic properties of thermo-hydro-mechanically modified bamboo (Guadua angustifolia Kunth) measured in tension, Key Engineering Materials, 600: 111-120.

Bartlett, A.I., Chapman, A., Roberts, A., Wiesner, F., Hadden, R.M. \& Bisby, L.A. 2018a. Thermal and flexural behaviour of laminated bamboo exposed to severe radiant heating. 2018 World Conference on Timber Engineering (WCTE 2018), 2018: Seoul, Korea.

Bartlett, A.I., Hadden, R.M. \& Bisby, L.A. 2018b. A Review of Factors Affecting the Burning Behaviour of Wood for Application to Tall Timber Construction. Fire Technology, 1-49.

Buchanan, A., Ostman, B. \& Frangi, A. 2014. Fire resistance of timber structures, National Institute of Standards and Technology Gaithersburg.

Buchanan, A.H. \& Abu, A. 2017. Structural design for fire safety/Andrew H. Buchanan, Anthony K. Abu, Chichester: John Wiley \& Sons Inc.

CEN 2004. Eurocode 5: Design of timber structures - Part 1-2: General - Structural fire design (EN 19951-2). Brussels: European Committee for Standardization.

CEN 2012. Timber structures - Structural timber and glued laminated timber - Determination of some physical and mechanical properties (EN 408:2010+A1). Brussels: European Committee for Standardization.

Chen, D., Liu, D., Zhang, H., Chen, Y. \& Li, Q. 2015. Bamboo pyrolysis using TG-FTIR and a labscale reactor: Analysis of pyrolysis behavior, product properties, and carbon and energy yields. Fuel, 148: 79-86.

Clauß, S., Joscak, M. \& Niemz, P. 2011. Thermal stability of glued qood joints measured by shear tests. European Journal of Wood and Wood Products, 69(1): 101-111.

Drysdale, D. 2011. An introduction to fire dynamics. Chichester: John Wiley \& Sons Inc.

Fernandez-Pello, A. \& Hirano, T. 1983. Controlling mechanisms of flame spread. Combustion Science and Technology, 32(1-4): 1-31.

Gutierrez Gonzalez, M., Madden, J. \& Maluk, C. 2018. Experimental Study on Compressive and Tensile Strength of Bamboo at Elevated Temperatures. 2018 World Conference on Timber Engineering (WCTE 2018), 2018: Seoul, Korea.

Gutierrez Gonzalez, M., Takeuchi, C. \& Perozo, M.C. 2012. Variation of tensile strength parallel to the fiber of Bamboo Guadua angustifolia kunth in function of moisture content. Key Engineering Materials, 517: 71-75.

Hidalgo López, O. 2003. Bamboo: The Gift of the Gods.

ISO, I.O.F.S. 2004a. Bamboo - Determination of physical and mechanical properties - Part 1: Requirements (ISO 22157-1:2004). Geneva: ISO.

ISO, I.O.F.S. 2004b. Bamboo - Determination of physical and mechanical properties - Part 2: Laboratory manual (ISO/TR 22157-2:2004). Geneva: ISO.

ISO, I.O.F.S. 2004c. Bamboo - Structural design (ISO 22156:2004). Geneva: ISO.

Jiang, Z., Liu, Z., Fei, B., Cai, Z., Yu, Y. \& Liu, X.E. 2012. The pyrolysis characteristics of moso bamboo. Journal of Analytical and Applied Pyrolysis, 94: 48-52.

Kaminski, S., Lawrence, A. \& Trujillo, D. 2016. Design Guide for Engineered Bahareque Housing. Beijing: International Network for Bamboo and Rattan (INBAR).

Liese, W. 1998. The Anatomy of Bamboo Culms. INBAR Technical Report Nº 18. In: International Network for Bamboo And Rattan, I. (ed.). Beijing: International Network for Bamboo and Rattan (INBAR).

Liu, Z., Jiang, Z., Cai, Z., Fei, B., Yu, Y. \& Liu, X. 2012. Dynamic Mechanical Thermal Analysis of Moso Bamboo (Phyllostachys heterocycla) at Different Moisture Content. Bioresources, 7(2): 1548-1557.

Mena, J., Vera, S., Correal, J.F. \& Lopez, M. 2012. Assessment of fire reaction and fire resistance of Guadua angustifolia kunth bamboo. Construction and Building Materials, 27: 60-65.

Mi, B., Liu, Z., Hu, W., Wei, P., Jiang, Z. \& Fei, B. 2016. Investigating pyrolysis and combustion characteristics of torrefied bamboo, torrefied wood and their blends. Bioresource Technology, 209: 50-55.

Östman, B., Brandon, D. \& Frantzich, H. 2017. Fire safety engineering in timber buildings. Fire Safety Journal, 91: 11-20.

Pettersson, O. 1986. Structural fire behaviour - development trends. LUTVDG/TVBB-3031-SE. Lund, Sweden: Department of Fire Safety Engineering and Systems Safety, Lund University.

Purkiss, J.A. \& Li, L.-Y. 2014. Fire safety engineering design of structures John A. Purkiss and Long-Yuan $\mathrm{Li}$, Boca Raton, Fla.: CRC Press.

Ramage, M.H., Sharma, B., Shah, D.U. \& Reynolds, T P.S. 2017. Thermal relaxation of laminated bamboo for folded shells. Materials \& Design, 132: 582-589.

Rasbash, D., Drysdale, D. \& Deepak, D., Critical heat and mass transfer at pilot ignition and extinction of a material. Fire Safety Journal, 1986. 10(1): 1-10. 
Reszka, P. \& Torero, J.L. 2016. Fire Behaviour of Timber and Lignocellulose. In Belgacem, N. \& Pizzi, A. (eds), Lignocellulosic Fibers and Wood Handbook: 555-581. Scrivener Publishing LLC.

Rizal, S., Shawkataly, A.K.H.P., Ikramullah, Bhat, I.U.H., Huzni, S., Thalib, S., Mustapha, A. \& Saurabh, C.K. 2018. Recent Advancement in Physico-Mechanical and Thermal Studies of Bamboo and its Fibers. In: Khalil, H.P.S.A. (ed.), Bamboo: Current and Future Prospects: 145-164. IntechOpen.

Sharma, B., Gatoo, A., Bock, M. \& Ramage, M. 2015. Engineered bamboo for structural applications. Construction and Building Materials 81: 66-73.

Solarte, A., Hidalgo, J.P. \& Torero, J.L. 2018. Flammability Studies for the Design of Fire-Safe Bamboo Structures. 2018 World Conference on Timber Engineering (WCTE 2018), 2018: Seoul, Korea.

Torero, J. 2016. Flaming ignition of solid fuels. In Hurley, M.J. et al. (eds), SFPE Handbook of Fire Protection Engineering: 633-661. New York: Springer.

Trujillo, D. \& López, L.F. 2016. 13 - Bamboo material characterisation. In Harries, K.A. \& Sharma, B. (eds), Nonconventional and Vernacular Construction Materials: 365-392. Elsevier Ltd.

Wang, G., Li, W., Li, B. \& Chen, H. 2008. TG study on pyrolysis of biomass and its three components under syngas. Fuel, 87: 552-558.

Wang, H., Zhang, X., Jiang, Z., Li, W. \& Yu, Y. 2015. A comparison study on the preparation of nanocellulose fibrils from fibers and parenchymal cells in bamboo (Phyllostachys pubescens). Industrial Crops and Products, 71: 80-88.

Wang, Y., Wang, G., Cheng, H., Tian, G., Liu, Z., Xiao Qun, F., Zhou, X., Han, X. \& Gao, X. 2009. Structures of Bamboo Fiber for Textiles. Textile Research Journal, 80: 334-343.

Xu, M., Cui, Z., Chen, Z. \& Xiang, J. 2017. Experimental study on compressive and tensile properties of a bamboo scrimber at elevated temperatures. Construction and Building Materials, 151: 732-741.

Yang, T.-H., Lee, C.-H., Lee, C.-J. \& Cheng, Y.-W. 2016. Effects of different thermal modification media on physical and mechanical properties of moso bamboo. Construction and Building Materials, 119: 251-259.

Yiping, L., Yanxia, L., Buckingham, K., Henley G. \& Guomo Z. 2010. Technical Report 32: Bamboo and Climate Change Mitigation. Beijing: International Network for Bamboo and Rattan (INBAR).

Zhang, Y.M., Yu, Y.L. \& Yu, W.J. 2013. Effect of thermal treatment on the physical and mechanical properties of phyllostachys pubescen bamboo. European Journal of Wood and Wood Products, 71: 61-67. 